\title{
Fronteiras da crítica literária brasileira: Oswald de Andrade e João do Rio na cena do novo
}

\author{
Sebastião Marques Cardoso*
}

\section{Resumo}

Em linhas gerais, o presente texto tem como objetivo apresentar uma releitura sobre o modernismo literário brasileiro. Na tentativa de romper com o olhar canônico sobre esse movimento, iremos analisar o discurso crítico de Oswald de Andrade [18901954]. Nossa intenção será a de apontar, no texto de Oswald, tanto aspectos impulsionadores de uma nova maneira de ver e fazer literatura quanto elementos ainda reminiscentes de uma cultura literária arcaica. Partindo da própria sugestão crítica de Oswald, iremos, em seguida, discutir com mais interesse, a presença de João do Rio [Paulo Barreto, 1881-1921] no imaginário do escritor paulista. Por fim, questionaremos a ideia de ruptura estética tout court no modernismo, sugerindo, no seu lugar, uma compreensão sobre o movimento mais abrangente, que possa incluir, também, autores remanescentes do período.

\section{Palavras-chave}

Literatura Brasileira do século XX. Oswald de Andrade. João do Rio. Revisão Crítica.

\section{Considerações iniciais e problematização}

Oswald de Andrade faz uma reflexão acerca da relevância das literaturas de cultura ibérica na construção do idealismo latino (ANDRADE, 1992). Em D. Quixote, de Miguel de Cervantes, o escritor paulista vê o elemento que une nossa contemporaneidade aos valores e anseios do velho mundo, e, também, o elemento que funda e inaugura, em nossos trópicos, o desejo ibérico de construção cultural. Quixote, à procura de Dulcinéia de Toboso - a mulher ideal-, embarcou na caravela dos descobridores, rumo à América do Sul. Essa simbologia estaria ligada às missões jesuíticas. No discurso crítico de Oswald, há uma certa modulação. A hipostação da cultura jesuítica não deve ser confundida com a hipostação da cultura do homem

* Doutor em Teoria e História Literária pela Universidade Estadual de Campinas. Professor Adjunto de Teoria Literária da Universidade do Estado do Rio Grande do Norte (UERN). 
simplesmente português. Oswald não nos surpreende ao apontar o padre latino como um dos elementos diversos, juntamente com o índio, o português e, posteriormente, o negro, responsáveis pela formação de nossa cultura, na sua fase inicial. Num estudo ainda instigante, Luiz Costa Lima (1981, pp. 3-9) mostra-nos que a cultura construída e herdada pelas missões jesuíticas resultou numa "cultura auditiva", avessa à reflexão e à teoria.

De acordo com Oswald de Andrade, a presença marcante e decisiva do padre latino em nossa gleba, em tempos remotos, fez com que a cultura do português, do índio e do negro se agregassem ao valor e à empresa da fé:

Reconhecendo a eficácia da fé no bom êxito das suas empresas, o português, que, sozinho, logrou resistir ao missionário, deu-lhe, nas primeiras assembléias do continente descoberto, uma ascendência preponderante. O índio politeísta não tardou a agregar um novo deus à sua mitologia, e o negro, habituado a ver em tudo manifestações sobrenaturais, deixou-se batizar com uma alegria de criança. (ANDRADE, 1992, p. 29).

O fenômeno do domínio intelectual "auditivo" do padre latino na formação histórica da sociedade sul-americana tornou-se uma tradição secular, cujo expoente maior, em inícios do século XX, no Brasil, foi, na análise de Oswald de Andrade, Alexandre Corrêa (1890-1984). Em seus primórdios, a "cultura auditiva", iniciada pela pregação do padre latino aos gentios, expandiu seu império através da escolástica; sobreviveu, em meados do século XIX, nos artigos de roda-pé; no século XX, nos discursos acadêmicos das universidades.

Entretanto, ao lado desse horizonte cultural "auditivo", existiu, segundo Oswald, "um movimento" nacional de "expressão superior", no início do século XX, no Brasil. Trata-se da obra de Farias Brito, seguida posteriormente por Jackoson de Figueiredo, Renato Almeida, Castro e Silva, Nestor Victorio, Almeida Magalhães, Xavier Marques, Perillo Gomes e Tasso Silveira. Hoje, autores pouco conhecidos e discutidos nas academias nacionais. Esse "movimento", porém não menos "auditivo" na nossa opinião, procurou se opor aos germanistas de Tobias Barreto e aos positivistas de Teixeira Mendes, ou seja, às duas correntes críticas mais aceitas e difundidas na época. Sem alongar nos detalhes sobre a fé panteísta do brasileiro, retratada na obra de Farias Brito, e de seus possíveis desdobramentos, Oswald de Andrade cita en passant João do Rio e Severiano de Resende como antecessores desse "movimento". Para Oswald de Andrade (1992, p. 30), As religiões no Rio, de João do Rio, e Meu Flos Santorum, de Severiano de Resende, precedem, como documentos, a obra de Farias Brito.

\section{Provincianismo e cosmopolitismo na vida cultural brasileira}

A afirmação de Oswald de Andrade de que o livro As religiões no Rio traz para o âmbito da literatura brasileira "um contigente pitoresco" insere a literatura do escritor carioca na rota do projeto de construção de uma identidade nacional, preconizado pelo 
escritor paulista, na década de 20 do século XX. Diante dessa possível aliança entre a literatura de João do Rio com o programa político-cultural de vanguarda, pensado por Oswald de Andrade, faremos, a partir de agora, algumas aproximações entre esse projeto oswaldiano e a literatura de João do Rio.

As religiões no Rio, obra publicada em 1904, teve uma tiragem pequena, cerca de mil exemplares, e logo se esgotou. (Cf. MAGALHÃES JÚNIOR, 1978, pp. 33-36). Reunindo as reportagens publicadas entre fevereiro e abril de 1904, na Gazeta de Notícias, do Rio de Janeiro, João do Rio aborda as religiões praticadas no Rio de Janeiro ainda desconhecidas pela imprensa e o grande público. (Cf. RODRIGUES, 1994, pp. 32-34). As reportagens causaram sensação e foram lidas avidamente. Muitos leitores duvidaram da veracidade das reportagens, considerando-as uma fantasia ou mesmo uma invenção de um escritor bastante imaginoso; outros, depois de publicadas em livro, consideram a obra um plágio de Les petites religions de Paris, de Jules Bois. (Cf MARTINS, 1976, p. 9).

O que fazia e pensava Oswald de Andrade em 1923 quando, presidida por Souza Dantas, embaixador brasileiro na França, resolve pronunciar a conferência "L'Effort Intellectuel du Brésil Contemparain", na célebre Universidade de Sorbone, no dia 11 de maio? A apresentação de sua conferência contou com o convênio da Academia Brasileira de Letras, com o patrocínio do Groupement des Universités e das Grands Écoles de France pour Rélations avec Amérique Latine. Esse texto de Oswald, ainda pouco conhecido, é considerado, ao lado do artigo "Pintura Nacional" e dos manifestos "Pau-Brasil" e "Antropófago", um dos pilares do ideário estético e político do nacionalismo de Oswald e, por extensão, da geração modernista ligada ao autor. (Cf. BOAVENTURA, 1995, p. 92; Cf. FONSECA, 1990, p. 128).

Oswald de Andrade, antes de sua viagem à Europa, era, porém, um escritor reconhecidamente convencional, embora tivesse apresentado, desde cedo, um espírito inquietante. Mesmo encabeçando, em fevereiro de 22, a barulhenta Semana de Arte Moderna, que contava com a participação de literatos como Ronald de Carvalho, Guilherme de Almeida, Menotti del Picchia e Mário de Andrade, a sua literatura, lida em viva-voz, não tinha nada de extraordinário à época. Os condenados, hoje Alma (o primeiro dos romances da Trilogia do Exílio, publicado recentemente pela Editora Globo), têm uma dimensão simbolista-decadente que não supera o período literário do momento nos termos propostos pelas vanguardas artísticas tout court. (Cf. CARDOSO, 2010). A viagem à Europa foi, para Oswald (e isso é inegável), fecundante. Na Europa, o escritor provinciano de São Paulo teve a possibilidade de se atualizar no âmbito das artes e, por conseguinte, a oportunidade (que não era para poucos) de mudar sua direção estética. Em outras palavras, foi durante a longa estada parisiense de 1923 que assomou a figura do escritor propriamente modernista que habitualmente costumamos ver recenseado nas histórias literárias nacionais. (Cf. DANTAS, 1991, p. 193; Cf. CASTELO; CANDIDO, 1997, p. 14).

Um pouco antes de 23, em dezembro de 22, Oswald de Andrade parte para a Europa a bordo do navio capitaneado pela Compagnie de Navegation Sud Atlantique. $\mathrm{Na}$ Europa, Oswald estreita suas relações de amizade com Tarsila do Amaral que, por sua vez, contribuiu grandemente para a sua introdução no meio artístico francês. 
O casal Tarsiwal, assim como eram chamados por Mário de Andrade, consolidou, em 23, suas relações, passando a residir no celeiro dos artistas, no quinto andar sem elevador do n. 9, Hégésippe Moreau - 18ème, Montmartre -, nas imediações da Place Clichy. Um pouco antes, porém, moraram no $\mathrm{n}^{\circ}$. 6, Le Chapelais- 17ème-. (Cf. BOAVENTURA, 1995, p. 84).

Passadas algumas semanas, após a sua apresentação em Sorbone, Oswald conhece, no final de maio do mesmo ano, Blaise Cendrars. O pirate du Lac Léman, como Oswald assim o chamou uma vez (pois Cendrars pretendia fazer fortuna financeira no Brasil), apresentou o casal de ricaços, vindos do Brasil, ao mundo intelectual francês. A partir do contato com o autor de Feulles de route, (cf. SOUSA, 1995) Oswald e Tarsila conheceram artistas como Brancusi, Jean Cocteau, Erik Saltie, Delaunay, Jules Romains, René Bacharach, De Chirico, Radiguet, Picabia, Aragon, Jean Giraudoux, John dos Passos, Jules Supervielle, Fernand Léger, Maximillien Gautier, Valéry Larbaud, André Lhote, Picasso e outros.

Blaise Cendrars ciceroniou o casal de noivos também nos hábitos mais distintos e elegantes de Paris. A agenda incluía: restaurantes "escolhidos"”, como Le Moustique, La Retonde de Montparnasse, La Tour d'Argent, Brasserie Lippe e os mais preferidos como o Clube dos 100 e a casa de Mme. Monteuil (em Les Halles); casas de shows (o cabaré Boeuf sur le Toi); a livraria La Maison des Amis des Livres de Adrienne Monnier; e indicações de marchands confiáveis, como Mr. Level e Ambrosie Vollard. Ainda nesse período, Oswald assistiu no Teatro do Champs Elysées a uma peça do amigo Cendrars, visitou a exposição de Arte Negra no Museu de Artes Decorativas e apreciou a apresentação das peças "Les Mariés de la Tour Eiffel", de Jean Cocteau, e "L'Homme et son désir", de Paul Claudel. (Cf. BOAVENTURA, 1995, p. 90).

Percebemos, depois de explicitados alguns dos roteiros culturais e gastronômicos de Oswald e Tarsila em Paris, que o casal encontrou, na França, uma tradição moderna estabelecida prestes a ser oficializada, contando com uma infraestrutura de mercado em plena atividade. A mercantilização da arte tinha tomado proporções tentaculares e complexas naquele meio. $O$ que assegurava o sustento e a independência à própria vanguarda funcionava, ao mesmo tempo, como agente de conflito e contra-ofensiva. Com isso, Oswald e Tarsila puderam perceber que, ao lado da discussão formal da estética moderna, existia uma cultura modernista francesa em curso arrefecida, conservadora e comercial. Então, o que se coloca em pauta não é exatamente o novo, mas a busca, no antigo, da sensação do novo.

A modernidade que se inscrevia em 23, na França, obrigou tanto os modernistas quanto os vanguardistas a operarem uma apropriação estética no contexto das envelhecidas rupturas modernas. A modernidade deixava de ser o sinônimo de progresso técnico e, agora, passava a incorporar os componentes regressivos deste último. A Arte Negra, exposta em Paris, foi o termômetro dessa nova conjectura. 0 "novo", agora, é obtido através da absorção de elementos residuais (locais, nacionais e tradicionais). Esses elementos, agraciados por Irlemar Chiampi de "contramodernidade", constituem uma nova metáfora para o novo na modernidade. A "contramodernidade" não significa uma negação do moderno. Trata-se, pois, da "outra face" do moderno. (Cf. CHIAMPI; MUTRAN, 1993, pp. 23-33). Mas o que explica exatamente essa pasmaceira e esse arrefecimento no paradigma da modernidade? 
Na primeira década do século $\mathrm{XX}$, Paris esteve no centro das muitas investidas, no âmbito das artes, consideradas as das mais valiosas e importantes dentro do empreendimento dos modernistas. Sua conhecida e tradicional fama de foco da cultura europeia, bem como a boa acolhida dada aos movimentos e tendências boêmicas do período anterior, atraíram os inovadores, como Diaguiév, Stravinski, os pintores cubistas, Apollinaire, Gertrude Stein, que se reuniam com frequência em Paris. Esses autores despertaram no público parisiense, com suas obras e depoimentos críticos, a consciência da precariedade da civilização, o que se tornaria mais agônica com a derrocada da Primeira Guerra Mundial.

Com o advento da Primeira Grande Guerra, as transformações culturais mais ousadas da Paris pré-guerra caem no refluxo, ao mudar de curso. Tida, antes da guerra, como um dos centros de revolta, durante a era de opróbrios, transformou-se em foco de conformismo belicoso. O centro da revolta se deslocou rapidamente para a Suíça. Em Zurique, por exemplo, nasceu, em 1916, o dadaísmo. Esse movimento artístico só chegaria, em Paris, no ano de 1920. Por volta dessa mesma época, o dadaísta Tristan Tzara irrompeu na cena literária de Paris, apresentando como poema um artigo de jornal lido ao som de sinos e guizos. Um pouco mais tarde, em 1924, a Paris ficaria mais uma vez abalada com o "Manifeste surréaliste". (Cf. CAHM in BRADBURY; MCFARLANE, 1989).

O modernismo e a experimentação cultural (e social) despertaram sistematicamente um protesto conservador moderado e um recuo reacionário extremista, pois o gosto estético do público parisiense era orientado e dominado pelos cânones do passado. Os cubistas, citando mais um exemplo, acharam mais difícil conquistar as galerias oficiais de Paris do que as de outras capitais; enquanto que, na mesma época, havia Picassos pendurados ao lado de Rembrants, em Amsterdã. Para o público parisiense do pré-guerra, Gide, Apollinaire e Marcel Proust, que é muito de se estranhar, continuaram sendo considerados figuras marginais, quase desconhecidas absolutamente. Como se não bastasse, os rebeldes políticos e sociais encontravam oposição política não só da liderança republicana, como também de uma linha expressiva e crescente de nacionalismo e xenofobia de direita.

Mesmo os rebeldes pré-1914 não foram inteiramente modernos se avaliarmos esse período com base na tradição clássica francesa e no período posterior, situado no contexto da revolução dos dadaístas, dos surrealistas e dos primeiros comunistas. Stravinski, os cubistas, Apollinaire e Gide não chegaram a romper totalmente como o passado. Dentro do sistema de valores do classicismo francês, esses rebeldes não representaram uma ruptura total com o conceito de uma ordem harmoniosa em questões políticas e culturais, com uma identificação da razão e da lógica como guias supremos, no entendimento dos mecanismos do universo e das origens da ação humana, e com uma concepção de homem vista em termos universais. Assim, a vanguarda parisiense pré-1914 não era completamente revolucionária no sentido em que o dadaísmo e o surrealismo viriam a ser nos anos posteriores à guerra. 0 dadaísmo e o surrealismo, movimentos que representaram em definitivo uma ruptura com o passado clássico francês, não foram criações autóctones dos franceses ou ligadas a eles. 
Ora, retornando à conferência de Oswald, agora poderemos melhor compreender as posições defendidas pelo autor naquele momento e procurar desvendar o mecanismo pelo qual esse texto oswaldiano adquiriu o status de crítica modernista no paradigma da modernidade literária brasileira. $O$ texto oswaldiano não tem a organicidade discursiva habitual. Lendo-o, dá-nos a impressão de uma rápida coletânea de pensamentos avulsos, sem nexos, independentes entre si e carentes de melhores detalhamentos. Uma paráfrase textual que obedeça a "linearidade" não linear de sua conferência seria, portanto, desastrosa, constituindo um vai-e-vem de recortes de uma cosmovisão altamente fragmentada. Após o comentário rasteiro da obra de Farias Brito, Oswald pincela autores e obras nacionais. Comenta o pensamento crítico brasileiro no âmbito da sociologia, da etnografia, da crítica literária, da literatura propriamente dita e das artes plásticas. Na literatura, Oswald faz uma sinopse que parte de Basílio da Gama até chegar aos seus contemporâneos (Ronald de Carvalho, Menotti del Picchia, Pedro Rodrigues de Almeida, Serge Milliet, Ribeiro Couto e Afonso Schmit).

Ora, a preocupação de Oswald de Andrade, no esforço de se ter uma literatura nacional, estava em sintonia com a preocupação dos franceses, resistentes às transformações mais radicais na cultura e na política, em manter a tradição clássica erigida sob a égide da ordem, da razão e da civilização. Nisso não existe, portanto, nada de novo; pelo contrário, como vimos nos parágrafos precedentes, a cultura francesa reagiu às tendências que representavam uma ruptura total com o modelo clássico francês desde as primeiras manifestações estéticas desse nível em inícios do século XX. Nesse sentido, o ambiente vivido por Oswald em 1923, em Paris, foi decisivo para que o escritor paulista cristalizasse seu gosto, ligado à classe dominante, ainda conservador em literatura, propondo uma literatura brasileira "pós-colonizada", mas de alcance restrito socialmente (falamos, sobretudo, do seu manifesto da poesia pau-brasil) em relação às manifestações literárias anteriores, como Os Sertões, de Euclides da Cunha, que toma uma dimensão de Brasil e de cultura literária mais abrangentes, e das Memórias Póstumas de Brás Cubas, de Machado de Assis, que circunscreve, no meio urbano, a vida social e política de uma classe dominante em um profundo desajuste ideológico. Em outras palavras, Oswald, em 1923, não assimilou, na íntegra, as mais ousadas manifestações artísticas, embora ele tivesse fartas notícias sobre elas; Oswald assimilou, com certeza, o preconceito a essas manifestações mais radicais, ao mesmo tempo em que procurou consolidar e apoiar sua postura conservadora em relação à literatura brasileira com base no discurso da ala menos progressista francesa, vinculando as raízes de nossa literatura às raízes clássicas e ao nacionalismo pernicioso e corrosivo em moda na França.

Buscar ou, melhor dizendo, forjar uma origem em literatura, cuja expressão dominante é a figura de um padre latino, caracteriza, sem dúvida, uma retórica autoritária e reacionária, que vincula as produções nacionais às clássicas raízes europeias:

Com efeito, Dom Quixote, atravessando o mar, não esqueceu as suas leituras. Ele gozava até ao desvairio e as proezas ideais. Assim, pois, a literatura brasileira acompanha primeiramente uma linha descendente para esbarrar no esforço nacional de Machado de Assis. É aí que ela começa a ter uma realidade superior ao mesmo tempo que nacional. (ANDRADE, 1992, p. 31). 
Oswald sugere uma literatura "brasileira", cuja formação parte da imitação do classicismo para, em seguida, ser incrementada de elementos e temas nacionais. Para o autor, a literatura de Machado de Assis representa apenas esse "esforço de construção nacional". Despojada de qualquer elemento retórico em moldes tradicionais, a "cultura auditiva" tem um lugar cativo no discurso crítico-ficcional de Oswald de Andrade. Simplesmente mágica, mítica e dogmática, é a intenção crítica e literária de Oswald de Andrade. A conferência de Oswald é débil teoricamente, mas o que a sustenta discursivamente não é a teoria. $O$ que garante o sucesso das aporias do "bovarista" paulista é, na verdade, o parque industrial de São Paulo e a antiga aristocracia do café.

O autoritarismo crítico de Oswald de Andrade tem sua parcela também no discurso ficcional. Há inumeráveis aspectos regressivos que condicionam a literatura do autor. (CF. HARDMAN, 2000, pp. 317-332). Num trabalho recente, Francisco Foot Hardman supera o "diapasão canônico" da crítica sobre Oswald ao destacar, no Manifesto da poesia Pau-brasil e na subsequente produção poética do autor, o uso do método naturalista, para a exploração das paisagens do país; o estabelecimento de uma origem mítica e autêntica (?); o congraçamento final da verdadeira (?) comunidade nacional; a conversão da barbárie em produto nacional e doméstico; e, também, um provincianismo piegas e um bairrismo patético, em vez de um diálogo satírico com a tradição romântica e um racismo mal dissimulado, bastante ao gosto da elite brasileira. Para o autor de o Trem fantasma, o "diapasão canônico consiste em atribuir à produção poética oswaldiana, em maior ou menor grau, o dom de conter um projeto estético e ideológico de um novo nacionalismo, libertário, sincero, natural, neológico, despojado, simples, alegre, espontâneo, autêntico, ao mesmo tempo antenado no tempo e no mundo e fincado no solo mais remoto das raízes pátrias". (HARDMAN, 2000, p. 320).

Mas o aspecto que nos parece mais corrosivo no discurso ficcional de Oswald de Andrade está ligado, exatamente, à sua constante política estética e ideológica "de exclusão da alteridade":

\begin{abstract}
A exclusão, aqui, não é aquela praticada pelo colonizador ocupante (e que, no limite, seguiu seu curso predatório e genocida). O gesto, neste caso, é algo mais sutil, mas não menos grave. Pois concede, aos de baixo, uma pseudovoz, esta será sempre representada como voz da subalternidade. Vai-se retratando, assim, uma série de tipos, figuras engraçadas e homens dignos de registro, porque rústicos, porque somente assim, subalternos, podem ser incorporados sem ameaça à ordem discursiva que se debruça até essa espécie de etnografia caricatural, passiva, feita de notações à moda de um turista espirituoso (Kodak excursionista), para que, em momento seguinte, os primitivos assim redescobertos sejam neutralizados como objetos meramente decorativos desse verdadeiro sentimento poético. (HARDMAN, 2000, p. 323).
\end{abstract}

Em face disso, reside, no discurso ficcional de Oswald, aqui nos restringimos à sua produção poética ligada ao projeto Pau-brasil, um autoritarismo político que, na ânsia de realizar um programa político-cultural de uma identidade nacional, acabou comprometendo sua dimensão puramente literária. Com isso, o "modernismo" não teria passado de um projeto político-cultural de hegemonia que objetivou, sobretudo, no discurso ficcional refundir um "neonaturalismo" de bases nacionais. 
O uso do adjetivo "pitoresco" em As Religiões no Rio, de Paulo Barreto, ao tentar sintetizar o valor da obra do escritor carioca, é novamente empregado por Oswald de Andrade ao tratar da literatura de José de Alencar. O "sentimento de brasileiro", que já se anunciava em Basílio da Gama, Gonçalves Dias e José de Alencar, aparece, neste último, recalcado à própria linguagem, através do uso de um código específico. $\mathrm{O}$ sentido de "pitoresco" em Oswald de Andrade aponta para um conceito de criação literária que não se exclui do cânone da literatura europeia, mas que opera com materiais e técnicas não ligadas necessariamente a essa tradição. Por isso, Oswald elogia a literatura de Alencar, pois o escritor romântico, no romance As minas de prata, faz uma leitura "brasileira", portanto, nacional, da tradição clássica literária que fundou, em nossos trópicos, a busca alegórico-utópica do idealismo latino. 0 explorador de minas ilusórias é uma nova alegoria quixotesca para a construção, no decênio de 60 de 1800, de uma cultura nacional, que se diferençasse da cultura lusitana. A brasilidade em Alencar residiria, então, numa operação básica: a incorporação de elementos, temas e formas distintos que fazem reviver, em nossa literatura, o mito fundador da tradição clássica: a busca da sagração do idealismo latino.

Entretanto, no meio intrincado do discurso oswaldiano, cheio de vai-e-vens de pensamentos avulsos e subitamente interrompidos, talvez por extrema ansiedade natural aos homens cosmopolitas ou por desinteresse mesmo em continuá-los, o autor brasileiro em Paris, tentando minimizar a importância de Alencar no cenário da construção de uma identidade nacional, conclui que o prosador romântico se deixou levar pela idealização falsa em $O$ Guarani e em Iracema. Com isso, José de Alencar não teria se "libertado da influência de importação que vinha ampliar o cenário dos novos páramos". (ANDRADE, 1992, p. 32). O discurso do proeminente autor do Manifesto Pau-brasil cai, no mesmo parágrafo, em absoluta contradição. Ao rejeitar a contribuição de Alencar, Oswald recorre à presença do negro no Brasil como elemento formativo de nossa cultura. Até aí não há nada de extraordinário, mas, no momento seguinte, tentando justificar essa presença, Oswald se apoia nas manifestações artísticas europeias cuja incorporação do elemento negro estava em moda: "Isto [o realismo do negro] observou-se ultimamente nas indústrias decorativas de Dakar, na estatuária africana, posta em relevo por Picasso, Derain, André Lothe e outros artistas célebres de Paris, na antologia, tão completa, de Blaise Cendrars". (ANDRADE, 1992, p. 32). Assim como, no Romantismo, o índio foi um elemento decorativo de uma literatura cuja expressão se desejava nacional, Oswald se apropria do elemento negro, com base no discurso modernista, na construção de uma literatura dita verdadeiramente nacional.

A partir dessa tentativa de ruptura com o processo ideológico imanente à literatura de José de Alencar, Oswald de Andrade instaura um discurso não menos pernicioso e circunstancial. O silogismo oswaldiano não é perfeito, mas suficiente o necessário para legitimar um discurso dito modernista e inovador. Na verdade, com isso, Oswald estabelece o modelo de modernismo brasileiro a ser seguido, ao mesmo tempo que se distancia indubitavelmente das vanguardas mais ousadas e extremadas da Europa. Nesse momento, o modernismo brasileiro assume por completo sua feição conservadora e autoritária no Brasil. 
A cultura e a raça africanas passam a configurar o elemento "pitoresco" indispensável na construção de uma literatura que se quer nacional. Neste cânone, proposto por Oswald, são incluídos Machado de Assis, Euclides da Cunha, Inglês de Sousa, Afrânio Peixoto, Aluísio Azevedo, Júlia Lopes de Almeida, Casimiro de Abreu e outros. Ao lado dessa corrente, há ainda mais duas: "a das vilas nascentes", que incluem Álvares de Azevedo, Alberto de Oliveira, Emílio de Menezes, Raimundo Corrêa, Francisca Júlia, Félix Pacheco, Cruz e Sousa, Alfonsus Guimarães, Olegário Mariano e Álvaro Moreyra, e a do "regionalismo", que incluem Ricardo Gonçalves, Cornélio Pires e Catulo da Paixão Cearense. Após esse levantamento de autores nacionais, Oswald conclui que, apesar dos esforços para se ter uma literatura nacional, faltam, ainda, "uma expressão e uma forma que podem dirigir nossa arte para o apogeu". (ANDRADE, 1992, p. 34).

A nova expressão, profetizada por Oswald de Andrade, procura estar em sintonia com o Brasil contemporâneo, traduzindo "a medida intelectual da sua mobilização industrial, técnica e agrícola". Como modelo dessa nova tendência, Oswald cita Monteiro Lobato e a "geração construtora", liderada por Paulo Prado, que incluem Mário de Andrade, Ronald de Carvalho, Guilherme de Almeida, Graça Aranha, Pedro Rodrigues de Almeida, Serge Milliet, Ribeiro Couto e Afonso Schmidt. Oswald, no esforço de erigir uma literatura brasileira "autêntica" (?), contou com toda uma geração de escritores e artistas jovens e talentosos, que poderiam muito bem encampar a bandeira do modernismo levantada por ele. Embora reconheça o valor documental da obra de João do Rio, na edificação do modernismo brasileiro, o escritor paulista em Paris o exclui do cânone da "geração construtora". Nisso, consiste um problema para a crítica de João do Rio, ao mesmo tempo em que essa negativa oswaldiana nos obriga a rever a crítica modernista empreendida por Oswald de Andrade.

A apreciação crítica de As religiões no Rio como obra de valor documental- que antecipa a obra de Farias Brito- obriga Oswald a rejeitá-la no paradigma da geração modernista, pois a obra, mesmo que trazendo à cena brasileira o elemento pitoresco de que fala Oswald de Andrade, não converte esse elemento em uma matéria artística que traduz com magnitude o processo de transformação na vida social, cultural e técnica do país. Em outro momento, Oswald, em comparação com os ensaios críticos de Monteiro Lobato, refuta novamente a contribuição de João do Rio no palco modernista de primeira linha e, com ele, a contribuição de muitos outros artistas, tais como Veiga Miranda, Albertino Moreira, Godofredo Rangel, Waldomiro Silveira, Elísio de Carvalho, Tomás Lopes e, em parte, Guilherme de Almeida. Diferentemente de Lobato, esses autores não saíram do "domínio puramente documental", com exceção de João do Rio e dos três últimos escritores. Estes, juntamente com João do Rio, teriam pecado, por sua vez, em ter introduzido, na própria atividade crítica, uma "visão histórica" (?) tipicamente urbana. Lobato, entretanto, fugiu e reagiu a esse meio. (ANDRADE, 1992, p. 34).

Essa concepção crítica de que a literatura de João do Rio é essencialmente urbana foi, também, compartilhada por Mário de Andrade. Mas, ao contrário da posição adotada por Oswald, que sobrevalorizou a literatura de Lobato em detrimento 
de algumas produções que se distinguiam pela geografia retratada, Mário - em um artigo dedicado a Machado de Assis, publicado no Diário de Notícias, de junho de 1939 - se mostrou simpático à literatura de João do Rio. Para o autor, João do Rio, bem como França Júnior, Lima Barreto e mesmo Aluísio de Azevedo (de O Cortiço), soube captar o sentido da cidade do Rio de Janeiro muito melhor que Machado de Assis. Este, por força de seu memorialismo, teria ancorado fundo as suas obras no Rio de Janeiro histórico que viveu, não se preocupando, com isso, em retratar o sentido que a cidade do Rio assumia para as novas gerações. (ANDRADE, 1993, pp. 57-58).

As religiões no Rio, série de reportagens publicadas em livro, reúnem doze reportagens sobre as religiões e cultos não oficiais praticados no Rio de Janeiro. Algumas dessas reportagens, como "No mundo dos feitiços", "O movimento evangélico" e "O satanismo", são mais longas e apresentam subdivisões, o que atesta que sua publicação na Gazeta de Notícias foi em pequenas parcelas. "No mundo dos feitiços" há cinco reportagens menores. "Os feiticeiros", texto que inicia o bloco de reportagens sobre as religiões e cultos africanos, foram publicados, pela primeira vez, em 9 de março de 1904, na Gazeta; seguidos de "As iauô", em 12 de março; "O feitiço", em 14 de março; "A casa das almas", em 16 de março; e, passadas algumas semanas, "Os novos feitiços de Sanin", em 29 de março de 1904. Este último trabalho encerra, portanto, o bloco destinado às religiões e cultos africanos no Brasil. "No mundo dos feitiços", João do Rio, com a ajuda de Antônio, negro bastante familiarizado com a cultura e os costumes africanos no meio carioca, procurou desvendar a cidade oculta que fervilhava de misticismo e feitiços muitos antes das estatuárias africanas e da Arte Negra chamarem a atenção de Oswald em Paris.

Oswald, quando alegou que As religiões no Rio trouxeram à literatura brasileira um "contingente pitoresco", devia ter em mente, sobretudo, a primeira reportagem que dá início ao livro. "No mundo dos feitiços" carrega, por força do interesse em desvendar um pouco dos mistérios da cultura negra no Brasil: um diferencial que Oswald procurava, em Paris, para a nossa literatura. Bem antes de 23, João do Rio havia mergulhado na cultura negra brasileira, tomou-a como matéria em suas reportagens e mostrou ao público letrado um Brasil bastante adverso da cultura oficial. Contudo, essa investida de João do Rio à cultura negra, "pitoresca" na percepção de Oswald, não chegou às raias da expressão modernista que Oswald tanto ansiava. 0 aspecto "contingente" reservado à obra do escritor carioca no movimento modernista pode estar ligado sensivelmente a diversos fatores. Dentre esses fatores, podemos destacar, hipoteticamente, alguns deles, todos marcados em itálico.

Da impossibilidade de João do Rio poder participar ativamente do movimento de renovação estética e cultural liderado por Oswald de Andrade, em decorrência da morte prematura do escritor carioca em 1921, momentos antes da Semana de Arte Moderna. Em entrevista realizada por Mário da Silva Brito, no Jornal de Notícias, em 26 de fevereiro de 1950, Oswald de Andrade (1995, pp. 159-165) disse que, depois de meio século de literatura, duas lembranças avultaram em sua memória: a de João do Rio e a de Mário de Andrade. Para o autor, esses escritores foram os homens mais importantes que já conheceu nesse período. Quanto à citação de Mário, não há nenhuma surpresa, pois Mário, além de amigo pessoal de Oswald, foi, com ele, um 
declarado paladino do ideário de renovação estética e cultural de São Paulo. Quanto à lembrança de João do Rio, há nela certo desconforto com relação à crítica tradicional do autor, que vê a literatura de Oswald como uma espécie de ícone a ser preservado. Depois desse flagrante, a literatura de Oswald poderia correr o risco de ser maculada, devendo reconhecer sua origem bastarda, atrelada a um contexto mais à margem. Não nos é de estranhar, portanto, declarações de que o escritor modernista de São Paulo estaria levemente equivocado, ao valorizar "figuras dissonantes", tais como João do Rio e Emílio de Meneses ao lado dos grandes modernistas de primeira linha. (BOAVENTURA, 1990, pp. 11-12).

A verdade é que Oswald de Andrade tinha João do Rio em alta conta. Num momento em que predominava o monopólio Bilac-Coelho Neto, João do Rio surpreendia Oswald de Andrade com seus contos magníficos, carregados de estilo decadista e art-nouveau, o que fazia dele um dos raros escritores nacionais que propunham uma renovação literária em nosso meio artístico em sintonia com os grandes centros de cultura internacionais. Porém, a morte prematura de João do Rio, em 1921, um ano antes da eclosão da Semana de Arte Moderna em São Paulo, teria representado um duro golpe tanto no projeto artístico de João do Rio quanto às projeções mais imediatas de Oswald que contavam com a participação de João do Rio. Num outro depoimento de Oswald de Andrade a Mário da Silva Brito, Oswald confessa que João do Rio era o escritor que melhor poderia encabeçar a Semana de Arte Moderna: "Não demorará muito o estouro dos futuristas. Já se estão preparando mesmo para a tomada de posições. Falta-Ihes apenas um pouco mais de organização e um sólido ponto de apoio, um nome ilustre que se disponha a comprometer-se na aventura. Oswald de Andrade pensa em João do Rio [...]" (BRITO, 1971, p. 133). Mesmo depois de alguns anos após a morte, João do Rio ainda continuava sendo alvo da crítica corrosiva de Antônio Torres. João do Rio causava irritação no cronista de Pasquinhas cariocas por ter pertencido ao grupo de escritores aureolados pela consagração social, como Afrânio Peixoto e Coelho Neto, e por ter defendido os interesses lusos no Brasil. Contudo, nem os críticos literários da época e tampouco os modernistas se manifestaram a respeito. Em 1925, João do Rio era uma figura literária que não mais chamava a atenção dos modernistas, embora tivesse preparado dois escritores modernistas de considerável envergadura: Ribeiro Couto e Peregrino Júnior. (Cf. BROCA, 1991, pp. 354-357).

Da relativa distância que o conjunto da obra de João do Rio estava cronologicamente das produções modernistas da década de 20. O período de renovação na vida social e, por extensão, na vida cultural, ocorre, quando falamos da literatura de João do Rio, nas duas primeiras décadas do século XX, no Rio de Janeiro. $\mathrm{Na}$ primeira década, houve, a partir do início compulsório das reformas urbanas empreendidas pelo prefeito Pereira Passos, uma série de medidas que visavam atribuir ao Rio de Janeiro um aspecto moderno, que substituísse o caráter do velho Rio imperial, bastante parecido com Lisboa, pelo modelo parisiense. Na década seguinte, assistimos ao ajustamento dessas ordens sociais, o antigo e o novo, na construção de uma outra e bizarra paisagem: a paisagem terceiro-mundista. Se avaliarmos com cuidado o conjunto da obra de João do Rio, perceberemos que o autor acompanhou muito bem o ritmo de modernização no Rio de Janeiro em escala ascendente e, depois 
de ter assistido ao seu ápice na Belle Époque brasileira, o seu movimento contrário, de declínio e estagnação no final da década de 20 . O processo de modernização, no Rio, foi lentamente perdendo suas forças mais atávicas e seu efeito entre os indivíduos que, nesse processo, participaram direta ou indiretamente. A obra de João do Rio, além de retratar essa aventura tecnológica, é resultado dela.

Nas primeiras produções do autor, presenciamos um escritor eufórico e internacionalista (um perfeito aprendiz de feiticeiro), preocupado em renovar o horizonte estético de nossa literatura, oferecendo ao público reportagens extraordinárias e contos maravilhosos que trazem às letras nacionais um estilo novo e que, no Brasil, não há tradição. Ao lado desse escritor eufórico e esnobe, existe também o grande e talentoso cronista melancólico que registra ora ansiosamente, ora pacientemente, a ambiguidade de vozes e atribulações desse período de constantes transformações. Por fim, nas últimas produções de João do Rio, seja no conto, na crônica ou, sobretudo, no romance $A$ correspondência de uma estação de cura, assistimos a um escritor completamente avesso à alegria, bastante apático e cético. Neste último João do Rio, já desiludido com o Rio, o autor, tanto criticado pela superficialidade com que travava suas personagens, faz com que elas, agora, ganhem vida própria, assumindo o papel de atores "absolutamente figurinos", como ingredientes de uma narrativa que atinge sua criticidade no grau máximo. (Cf. CARDOSO, 2011).

O que João do Rio viveu em duas décadas, certamente muitos artistas não viveram em uma vida inteira. Quando Oswald dava os seus primeiros passos na crítica teatral e na literatura, João do Rio já era considerado um escritor consagrado. Em 1915, quando João do Rio, sob a direção de Adelina Abranches, torna pública tanto no Rio quanto em São Paulo a sua peça Eva, Oswald faz uma crítica bastante elogiosa à peça do autor carioca. No ano seguinte, em parceria com Guilherme de Almeida, Oswald publica as peças Mon coeur balance e Leur âme. De alguma forma, João do Rio teria contribuído com sua literatura e sua visão crítica na formação literária e, no mínimo, crítica de Oswald de Andrade. No Rio, Emílio de Menezes sugeriu a sua apresentação na Escola Dramática, com a concordância de Alberto de Oliveira e João do Rio. Não nos surpreende, portanto, encontrar um exemplar, hoje raríssimo, das peças de Oswald e Guilherme de Almeida na biblioteca pessoal de João do Rio, com a seguinte inscrição: "A João do Rio, le maître du Theâtre Brésilien", assinada pelos autores. (BOAVENTURA, 1995, pp. 42-44). Corrido mais um ano, em 1917, João do Rio publica A correspondência de uma estação de cura.

Dois homens das letras nacionais, opostos, mas justapostos. Quando João do Rio, a duras penas, atingiu a sua maturidade literária, Oswald aprendia com o mestre do modernismo no Rio as primeiras lições de arte e tecnologia. Ambos unidos e motivados por uma mesma razão: o desejo de fazer uma nova literatura no Brasil que levasse em conta a dinâmica da modernização. Contudo, no momento em que os primeiros modernistas paulistas e cariocas que vieram a reboque começaram a aparecer no horizonte técnico-industrial e artístico de São Paulo, a produção literária de João do Rio já não era mais vista como uma novidade no meio literário brasileiro. Isso teria contribuído negativamente na avaliação, empreendida por Oswald de Andrade, da literatura de João do Rio no contexto das inovações estéticas que o escritor paulista estava propondo. 
Da ignorância de Oswald de Andrade em relação ao discurso ficcional e crítico de João do Rio. A maior desventura de João do Rio foi ter nascido num meio ainda não preparado para o receber. Mestre da graça intelectual, ironia e sátira misturadas, e mestre da arte de transformar o jornal em obra de arte, o escritor carioca foi também filósofo leviano e formulador sarcástico das pequenas sínteses históricas de nosso tempo. (AMADO, 1971, pp. 28-30). João do Rio foi, para Gilberto Amado, o jornalista mais venturoso que desabrochou num homem de letras. Autor de uma vastíssima obra que compreende crônicas, reportagens, romances, peças de teatro e contos, Paulo Barreto também escreveu conferências reunidas intitulando Psicologia Urbana. O contrato para a publicação da obra foi firmado em dezembro de $1910 \mathrm{com}$ a Casa Garnier. Nele incluía, além da publicação de Psicologia Urbana, mais três obras. A saber: Vida Vertiginosa, Portugal d'Agora: Lisboa antes da República e A Profissão de Jacques Pedreira. (Cf. MAGALHÃES JUNIOR, 1978. p. 144).

O escritor, a convite de Olavo Bilac e Medeiros e Albuquerque, entrou na onda de conferências em fins de 1905 com uma conferência sobre "O Amor carioca". E fez depois mais três: "O Figurino", "O Flirt" e "A Delícia de Mentir". Ao contratar João do Rio à publicação do livro Psicologia Urbana, a voga das palestras literárias tinha chegado, contudo, ao fim. (MAGALHÃES JÚNIOR, 1978, pp. 137-138). Há, ainda, em Psicologia Urbana, o discurso de posse do escritor como acadêmico. Em setembro de 1909 faleceu em Paris o poeta Guimarães Passos. Dois meses depois, João do Rio lançou-se candidato à cadeira cedida pelo poeta da geração "boêmia", conseguindo apoio dos "civilistas" cujo artífice maior era Rui Barbosa, o então presidente da Academia Brasileira de Letras. Além do apoio dos civilistas, João do Rio contava também com a simpatia de Medeiros e Albuquerque. Resultado: em sete de maio de 1910, a Academia elegeu João do Rio, depois de duas tentativas frustradas, como membro dessa instituição. (Cf. RODRIGUES, 1996, pp. 103-106). Mas foi em 12 de agosto deste mesmo ano que aconteceu a cerimônia de posse do escritor, no prédio do silogeu. Para além do esnobismo do cronista, o discurso de posse como acadêmico esteve em perfeita sintonia com as ideias do autor desde os tempos de $A$ Cidade do Rio. Para João do Rio, a arte devia estar, queiramos ou não, de algum modo vinculada à época em que foi concebida. (Cf. RODRIGUES, 1996, pp. 116-117). É por isso, talvez, que Gilberto Amado, em 1911, diz que Psicologia Urbana, bem como outros livros do autor, está cheio do encanto e da personalidade particularíssima do autor. (AMADO, 1971, p. 30).

As palavras de Gilberto Amado não foram, contudo, suficientes para legitimar o discurso ficcional e crítico de João do Rio. Relendo o "Discurso de recepção", encontramos nele mais do que elementos que fundamentam a sua trajetória ficcional, os pressupostos críticos que podem ligar o seu discurso crítico ao conjunto de escritores e artistas ligados ao projeto modernista de Oswald de Andrade. Muitos autores, que nem sequer produziram um discurso ou uma literatura "que sabem ser" modernistas, foram incorporados ao cânone modernista estabelecido por Oswald de Andrade em troca de apoio à sua empresa. Estes são lembrados ainda hoje, em nossa história literária, como escritores representativos desse período, enquanto que, João do Rio, o escritor que mais se envolveu com o discurso modernista num tempo em que predominava um gosto literário completamente morno e apático, não aparecia ainda 
recentemente nos livros de história literária, quando aparece é visto também como uma figura literária menor, típico representante do gosto literário comum do período "pré-modernista", que pouco contribuiu para a renovação de nossa literatura. Enfim, João do Rio teria sido excluído do cânone modernista da literatura brasileira, estabelecido por Oswald de Andrade, não por demonstrar uma incompatibilidade ficcional e crítica ao projeto de renovação cultural e artística de São Paulo, mas porque a informação de sua literatura e do seu discurso crítico teriam chegado a ele de maneira tendenciosa ou turva demais. Embora Oswald admirasse João do Rio, chegando a ver nele o homem ilustre e bem relacionado politicamente que garantiria o sucesso da Semana de Arte Moderna em São Paulo, o escritor paulista demonstrava um profundo desconhecimento acerca da modernidade da literatura e do discurso crítico que João do Rio tão habilmente empregava.

Da crença de que o domínio do escritor carioca se restringia tão-somente à vida política e cultural do Rio de Janeiro. Embora o berço e quase a totalidade da obra de João do Rio demarque geograficamente a cidade do Rio de Janeiro, o escritor carioca não foi um escritor exclusivamente do Rio de Janeiro. Na sua vasta obra, há crônicas, reportagens, um romance e uma peça teatral que não são exatamente ambientados no Rio de Janeiro. João do Rio retratou os páramos mineiros em Os dias passam [...], publicou um artigo no periódico argentino El País, cobriu, como correspondente brasileiro no Tribunal de Haia, o término da Primeira Guerra em "Na conferência da $\mathrm{Paz}^{\prime \prime}$, retratou a riqueza do interior paulista em Eva, encantou-se com Lisboa em Portugal d'agora e em Fados, canções e danças de Portugal, e, ao engajar-se na campanha civilista, visitou a cidade de São Paulo, deixando marcas indeléveis que confirmam o seu crescente envolvimento com a cidade bandeirante. João não foi só do Rio, foi também João da Europa, João da Argentina, João de Minas, João de Ribeirão Preto e, por que não, João da Garoa.

Em se tratando da visita de João do Rio à cidade de São Paulo, em 1915, podemos lembrar a sua triunfal chegada à cidade num noturno de luxo, da sua hospedagem no elegante hotel Rôtisserie Sportsman e das suas conferências proferidas no teatro Santana, em benefício do Centro Acadêmico 11 de agosto, da Faculdade de Direito. (Cf. BROCA, 1991, pp. 328; Cf. RODRIGUES, 1996, p. 119). Mesmo depois de alguns anos após sua morte, João do Rio ainda sobrevive na memória paulistana através da reedição de uma de suas crônicas pelas oficinas gráficas do Jornal do Brasil, carregada de nacionalismo e amor à civilização paulista: "São Paulo é o único Estado que absorveu a imigração e não foi por ela absorvido". (RIO, 1929, p. 5).

Isso posto, João do Rio participou, como substrato, do modernismo paulista. O alcance de sua literatura não deve ficar somente restrito à cidade do Rio, como homologia de seu pseudônimo. João do Rio não teria recusado o convite de Oswald para integrar o clube dos seletos, pois não havia, por parte de João do Rio, qualquer objeção. Momentos antes da Semana, João do Rio havia fundado, no Rio de Janeiro, o jornal A Pátria; isso significa, como o próprio nome do jornal sugere, que o escritor estava no mesmo caudilho nacionalista por que passavam os "meninos" de São Paulo. 
Da necessidade de ocultar sobremaneira as realizações e produções artísticas mais extremadas que precediam ou corriam em paralelo ao modernismo paulista, para, com isso, não arrefecer o impacto desse movimento no âmbito político das letras nacionais. Para iniciar essa discussão, gostaria de lembrar um chiste de Mestre Cook, publicado na coluna "Pratos leves", em A Gazeta, de São Paulo, de 9 de fevereiro de 1922: "A comissão convidou vários literatos do Rio para tomarem parte na festa. / Não concordamos. A Semana devia ser rigorosamente paulista. E literatos- louvado seja Deus!- não nos faltam. Há-os até demais". (COOK, 2000, p. 357). A empresa modernista assumia posições hegemônicas, como podemos perceber através da leitura do chiste de Mestre Cook. Porém, sustentar um movimento artístico tipicamente regional, circunscrito à paisagem de São Paulo e sob a ajuda divina (o que fere e questiona em demasia o espírito modernista do grupo), como um evento puro de proporções nacionais e simplesmente sem a participação de mais ninguém do âmbito da cultura nacional, soaria como algo profundamente tendencioso e falso. Quando Oswald inclui Graça Aranha e outros artistas do Rio, o escritor paulista tenta, na verdade, vender a ideia da amplitude do movimento na cultura nacional. Com isso, Oswald justifica e naturaliza uma filosofia estética que, em última análise, diz respeito tão-somente à vida de um grupo restrito à geografia de São Paulo, vendida como produto representativo de toda a cultura nacional que se quer distinta do futurismo e do "provincianismo": "Depois de Graça Aranha ter dado a sua Estética da Vida, colossal golpe nos arraiais frouxos do passadismo em com a atuação sempre admirável e aliás tradicional de Ronald de Carvalho e seus amigos, o movimento não pode mais ser chamado futurista nem paulista. Trata-se de um movimento nacional, violento e triunfante e no qual se empenham reputações formidáveis". (ANDRADE, 2000, p. 108).

Podemos aventar, finalmente, que a participação de João do Rio muito incomodaria a elite paulistana, pois sua presença redimensionaria o horizonte estéticopolítico, ligado à indústria e à agricultura paulistas, para uma possível onda de lusitanismos. É sabido, pois, que João do Rio, em parceria com João de Barros, mantinham uma revista binacional, chamada Atlântida, que tinha o propósito de estreitar os laços culturais entre Brasil e Portugal. Isso, de alguma maneira, poderia não só mudar o curso do movimento de renovação estética de São Paulo, como, também, poderia arrefecer sensivelmente o alcance político do modernismo paulista. Não nos é de estranhar, portanto, o elogio, apesar das divergências estéticas, de Oswald de Andrade à literatura de Monteiro Lobato e o constante assédio para que o autor de $O$ Jeca Tatu fizesse parte da Semana de Arte Moderna. Lobato era um ótimo patrocinador! Com a recusa de Lobato, Oswald providenciou, em última hora, um outro representante. Mesmo do Rio, Graça Aranha tinha ótimas relações políticas.

\section{Considerações finais}

A trajetória desse texto reflexivo acerca de João do Rio e Oswald de Andrade, tendo como ponto de partida a conferência do escritor paulista, apontou para algumas conclusões críticas. Reside no discurso ficcional e crítico de Oswald de Andrade um 
autoritarismo na empostação da linguagem, o que nos faz crer que sobrevive em Oswald a "cultura auditiva" de que fala Luiz Costa Lima; a "cultura auditiva" no discurso crítico de Oswald está em sintonia com o período remansoso que as artes atravessam na Paris dos anos 20; a conferência "L'Effort Intellectuel du Brésil Contemparain" foi analisada com vista no contexto de sua produção e de sua recepção crítica na historiografia literária brasileira; as negativas oswaldianas à literatura de João do Rio auxiliaram significativamente para a exclusão do escritor carioca do projeto de renovação na literatura proposto no período; em decorrência das negativas de Oswald, faz-se necessário rever o paradigma da modernidade literária paulista com vistas nas interdições à literatura de João do Rio; e, com base nessas interdições, há uma série de hipóteses que poderiam ter condicionado tanto o pensamento crítico de Oswald quanto o dos críticos e escritores contemporâneos de João do Rio.

Dessas interdições, surgiria um senso comum na crítica de João do Rio, como um escritor menor e superficial, que traduz o "sorriso da sociedade" restrito ao Rio de Janeiro, ressoando estridentemente nas histórias literárias nacionais. Somente a partir da década de 80, Flora Süssekind e outros pesquisadores acadêmicos resolveram reeditar algumas obras de João do Rio e trazer, de volta, a importância da modernidade literária do escritor, na historiografia literária nacional.

Para finalizar, se é lícito falar em modernismo em Oswald, é lícito igualmente falar em modernismo em João do Rio. Tanto um e outro têm suas rupturas estéticas, o que pode caracterizar uma nova técnica artística, porém essas rupturas não chegam a destruir por completo as velhas concepções e amarras anteriores. Os autores (re)enquadraram esteticamente suas produções literárias, profundamente mestiças de nascença e comprometidas até o pescoço com a ideologia oficial da época. Assim sendo, o modernismo paulista, desejando ainda manter essa premissa, deverá se acostumar a reconhecer outros modernismos afora.

\section{Referências}

AMADO, G. Paulo Barreto. In: A chave de Salomão e outros escritos. 4. ed. Rio de Janeiro: José Olympio Editora, 1971.

ANDRADE, M. de. Machado de Assis - [I]. In: Vida Literária. Pesquisa, estabelecimento de texto, introdução e notas por Sônia Sachs. São Paulo: Hucitec; Edusp, 1993.

ANDRADE, O. de. Futuristas de São Paulo. In: BOAVENTURA, M. E. (org.). A Semana de Arte Moderna vista pelos seus contemporâneos. São Paulo: Editora da Universidade de São Paulo, 2000. Este texto, catalogado por Maria Eugênia, foi publicado originalmente no Jornal do Comércio, São Paulo, em 19 de fevereiro de 1922.

Os dentes do dragão: entrevistas. São Paulo: Globo: Secretaria de Estado da Cultura, 1990.

O esforço intelectual do Brasil contemporâneo. In: Estética e Política.

Pesquisa, organização, introdução, notas e estabelecimento do texto de Maria Eugenia 
Boaventura. São Paulo: Globo, 1992. Essa conferência, de Oswald de Andrade, foi inicialmente publicada em francês na Revue de l'Amerique Latine 2, n. 5, Paris, 1923, pp. 197-207; em português, na Revista do Brasil, n. 96, São Paulo, dezembro de 1923, pp. 383-89.

BOAVENTURA, M. E. O salão e a selva: uma biografia ilustrada de Oswald de Andrade. Campinas, SP: Editora da UNICAMP; São Paulo: Editora Ex Libris, 1995.

Os dentes do dragão Oswald. In: ANDRADE, O. de. Os dentes do dragão: entrevistas. São Paulo: Globo: Secretaria de Estado da Cultura, 1990.

BRITO, M. da S. O escultor taciturno. In: História do modernismo brasileiro: antecedentes da Semana de Arte Moderna. 3. ed. Rio de Janeiro: Civilização Brasileira, 1971.

BROCA, B. Naturalistas, parnasianos e decadistas: vida literária do realismo ao pré-modernismo. Campinas, SP: UNICAMP, 1991.

CAHM, E. Revolta, conservadorismo e reação em Paris, 1905-25. In: BRADBURY, M.; MCFARLANE, J. Modernismo: guia geral. São Paulo: Companhia das Letras, 1989.

CARDOSO, S. M. João do Rio: espaço, técnica e imaginação literária. Curitiba: CRV Editora, 2011.

Oswald de Andrade: anti-heroísmo, literatura e crítica. Curitiba: CRV Editora, 2010.

CASTELLO, J. A.; CANDIDO, A. Grupos e tendências. In: Presença da literatura brasileira. Modernismo: história e antologia. 10 ed. Rio de Janeiro: Bertrand Brasil, 1997.

CHALMERS, V. 3 linhas e 4 verdades. 0 jornalismo de Oswald de Andrade. São Paulo: Duas Cidades, 1976.

CHIAMPI, I.; MUTRAN, M. H. (org.). A questão da modernidade. Caderno 1. São Paulo: FFCH/USP, 1993.

COOK, M. Bicho-papão. In: BOAVENTURA, M. E. (org.). A Semana de Arte Moderna vista pelos seus contemporâneos. São Paulo: Editora da Universidade de São Paulo, 2000.

DANTAS, V. Oswald de Andrade e a poesia. In: et alii. Revista Novos Estudos. Julho de $1991, n^{\circ} .30$.

FONSECA, M. A. Oswald de Andrade: biografia. São Paulo: Art Editora: Secretaria de Estado da Cultura, 1990.

HARDMAN, F. F. Algumas fantasias de Brasil: o modernismo paulista e a nova naturalidade da nação. In: DECCA, E. S. de; LEMAIRE, R. (org.) Pelas margens. Porto Alegre, RS: UFRGS; Campinas, SP: UNICAMP, 2000.

LIMA, L. C. Concepção de história literária na Formação. In: D'INCAO, M. A. ; SCARABÔTOLO, E. F. (orgs). Dentro do texto, dentro da vida: ensaios sobre Antonio Candido. São Paulo: Companhia das Letras; Instituto Moreira Salles, 1992. 
LIMA, L. C. Dispersa demanda: ensaios sobre literatura e teoria. Rio de Janeiro: Francisco Alves, 1981.

MAGALHÃES JÚNIOR, R. Reportagens que serão livros. In: A vida vertiginosa de João do Rio. Rio de Janeiro: Civilização Brasileira: INL, 1978.

MARTINS, L. Introdução. In: RIO, J. do. As religiões no Rio. Rio de Janeiro: Nova Aguilar, 1976.

RIO, J. do. A propósito de uma parada da Força Pública no prado da Mooca, em S. Paulo, em 15 de novembro de 1915. In: Um gesto para a história. Rio de Janeiro: [Off. Gráficas do Jornal do Brasil], 1929.

RODRIGUES, J. C. Cinematógrafo vertiginoso e a alma das ruas. In: João do Rio: uma biografia. Rio de Janeiro: Topbooks, 1996.

João do Rio: catálogo bibliográfico. Rio de Janeiro: Secretaria Municipal de Cultura, Departamento Geral de Documentação e Informação Cultural, Divisão de Editoração, 1994.

SOUZA, A. de. O. Cendrars tradutor do Brasil: um estudo da tradução francesa de A Selva de Ferreira de Castro. São Paulo: Annablume, 1995.

\section{Titre}

Frontièrs de la critique littéraire brésiliènne: Oswald de Andrade et João do Rio dans la scène de la nouvelle

\section{Résumé}

Comme sujet majeur, cet article va présenter une relecture sur le "modernisme littéraire" du Brésil ou, autrement dit, sur I'avant-guarde de l'art brésilien du XXe siècle. En essayant de couper la perspective du canon de ce mouvement littéraire, nous irons analyser le discours critique de Oswald de Andrade [1890-1954]. Nous avons l'intention de montrer, dans le texte de Oswald, les aspects moteurs d'une nouvelle manière de voir et faire littérature et, d'autre façon, les éléments encore reminiscents d'une culture littéraire archaïque. À partir de la même critique de Oswald, nous irons discuter, tout de suite et avec patience, la présence de João do Rio [Paulo Barreto, 1881-1921] dans l'imaginaire de l'écrivain de São Paulo. À la fin, nous irons mettre en question I'idée de rupture esthétique tout court dans l'art du "modernisme" brésilien. Nous allons suggérer une compréhension plus élargie sur le mouvement dont il peut inclure aussi les auteurs descendants de la période.

\section{Mots-clés:}

Littérature Brésiliènne du XXe siècle. Oswald de Andrade. João do Rio. Révision Critique.

Recebido em 17/12/2011. Aprovado em 28/06/2012. 